\title{
Effect of support availability, mother plant genotype and maternal support environment on the twining vine Ipomoea purpurea
}

\author{
Ernesto Gianoli* and Marcia González-Teuber \\ ECOBIOSIS, Departamento de Botánica, Universidad de Concepción, Casilla 160-C, Concepción, Chile; \\ *Author for correspondence (e-mail: egianoli@udec.cl)
}

Received 12 March 2004; accepted in revised form 24 December 2004

Key words: Germination, Maternal effects, Phenotypic plasticity, Physical support, Seed size, Vines

\begin{abstract}
In the twining vine Ipomoea purpurea we experimentally assessed the effect of support availability (a vertical stake), maternal genotype (family), and maternal environment (presence or absence of support in mother plants) on morphological traits, accounting for differences in initial seed size. While there was no effect of the maternal environment on seed size at the family level, families within each maternal environment did differ in seed size. Seeds from families of supported mothers showed higher germination than those from families of unsupported mothers. The maternal environment did not influence shoot traits but affected phenotypic plasticity in the number of leaves in response to support. Thus, whereas progeny plants from unsupported mothers did not show a response to support availability in the number of leaves, progeny from supported mother plants had a greater number of leaves once support was provided. The maternal genotype only affected the number of leaves.
\end{abstract}

\section{Introduction}

The maternal environment may affect plant phenotype (Roach and Wulff 1987; Donohue and Schmitt 1998). Maternal environmental effects are often mediated by seed size (Roach and Wulff 1987; Platenkamp and Shaw 1993; Schmid and Dolt 1994). This variation in seed size of the progeny may be a consequence of differential seed provisioning by mother plants due to variation in availability of resources such as nutrients and moisture (Rossiter 1996; Sultan 1996), and explains why most maternal effects are observed only during early stages of plant development (Miao et al. 1991; Wulff and Bazzaz 1992). The relative importance of maternal environmental effects vs. maternal genotype on plant phenotype has received contrasting evidence (Schmitt et al. 1992; Sultan 1996; Weiner et al. 1997). There is ample evidence that the phenotype of progeny plants may be affected by their environmental conditions of growth (Schlichting and Pigliucci 1998). This phenotypic plasticity might also be influenced by the environment experienced by mother plants (Galloway 1995). Maternal effects on phenotypic plasticity would be advantageous if the capacity of the progeny to respond to a given environment is enhanced when mother plants have experienced such environment. Differences in phenotypic plasticity among maternal families would indicate genetic differences in the capacity of plants to respond to a given environment.

Climbing plants (vines) depend on the availability of physical support to occupy favourable 
positions along the vertical light gradient (Putz and Mooney 1991). Vines that locate a suitable support generally have a greater biomass and reproductive output than those that grow unsupported (Putz 1984; Gianoli 2002). It has been recently reported that the twining vine species Ipomoea purpurea shows phenotypic responses to the availability of support, and that some of these responses are affected by the maternal environment (support) (Gianoli 2002, 2003). In the present work, we experimentally assessed the effect of maternal environment (presence or absence of support), maternal genotype (family), and support availability on morphological traits of I. purpurea, accounting for differences in initial seed size. Evaluation of the ANOVA statistical interactions between support availability and both maternal environment and maternal genotype allowed us to test for the existence of maternal environmental effects on phenotypic plasticity and genetic differences in phenotypic plasticity, respectively.

\section{Materials and methods}

Ipomoea purpurea (L.) Roth (Convolvulaceae) is a self-compatible annual herbaceous vine. The stems (0.5-2 m long) are twining when physical support is available. Fruits contain 6 seeds $(4 \mathrm{~mm}$ long, $2.5 \mathrm{~mm}$ wide). I. purpurea is distributed throughout the Americas (Austin and Huamán 1996) and in Chile occurs mainly in orchards, pastures, and forest edges (Matthei 1995).

The maternal plants originated from seeds collected in the edge of orchards in Central Chile. Plants were grown with and without physical support during two generations. Support consisted of a vertical plastic stake $(0.8 \mathrm{~cm}$ diameter, $1.8 \mathrm{~m}$ long) placed just in contact with the stem. Plants were individually planted into plastic pots (5 1) filled with potting soil and transferred to an experimental plot. The plot was located outdoors, in the campus of Universidad de Chile, Santiago $\left(33^{\circ} 28^{\prime} \mathrm{S} ; 70^{\circ} 38^{\prime} \mathrm{W}\right)$, within an enclosure of wire netting $(16 \mathrm{~m} \times 8 \mathrm{~m})$, and was previously weeded and covered with a layer of coarse sand. Experiments were performed during the austral summer (first generation: November 1999-February 2000; second generation: November 2000-February 2001), at a range of maximum and minimum temperatures of $29 \pm 3{ }^{\circ} \mathrm{C}$ and $12 \pm 3{ }^{\circ} \mathrm{C}$, respectively, and an average day length of $15 \mathrm{~h}$. Full daylight in clear days reached an average value of $1990 \mu \mathrm{mol} \mathrm{m}^{-2} \mathrm{~s}^{-1}$ PAR. According to the Mediterranean-type climate of the region, no precipitation occurred during the growth of maternal plants. These plants were used for experiments reported earlier (Gianoli 2002, 2003).

The progeny plants were obtained from seeds of the plants that grew either supported or unsupported for two generations. Four maternal families for each support treatment (10 seeds per family) were chosen. Seeds were weighed, scarified and germinated. Seed scarification consisted of immersion in concentrated sulphuric acid for $5 \mathrm{~min}$ followed by washing in running tap water. Seeds were germinated in a room at $20 \pm 1{ }^{\circ} \mathrm{C}$ on wet filter paper in covered plastic boxes and planted in plastic pots $(500 \mathrm{ml})$ filled with potting soil. The percentage of germination for each maternal family was recorded. One week after seedlings attained the second true leaf they were transplanted into plastic pots (5 1) filled with potting soil and transferred to a glasshouse. The glasshouse was located in the campus of Universidad de Concepción, Concepción (36 $46^{\circ} \mathrm{S}$; $\left.73^{\circ} 3^{\prime} \mathrm{W}\right)$. The experiment was performed during the austral summer (January-February 2003), at mean maximum and minimum temperatures of 25 and $12{ }^{\circ} \mathrm{C}$, respectively, and a day length of $16 \mathrm{~h}$. Light levels in clear days in the glasshouse reached values of ca. $1100 \mu \mathrm{mol} \mathrm{m}{ }^{-2} \mathrm{~s}^{-1}$ PAR.

Four weeks after plants were transferred to the glasshouse, approximately half of the seedlings within each of the eight maternal families (four families for each maternal treatment) were supplied with physical support (vertical stakes), as described above for maternal plants. This rendered 3-5 individuals per family per treatment. The 61 plants (29 from unsupported mothers, 32 from supported mothers) were placed alternately on benches in the glasshouse. Inter-pot distances were sufficient to prevent mutual shading. Plants were watered with tap water to field capacity every third day. Ten weeks after plants were transferred to the glasshouse, stem diameter and the length of three consecutive internodes at mid shoot were measured using a digital calliper $(0.01 \mathrm{~mm}$ resolution). Stem length, number of branches, number of leaves, and number of flowers were also recorded. The shoot was harvested, dried $\left(48 \mathrm{~h}\right.$ at $\left.80^{\circ} \mathrm{C}\right)$ and weighed. 
A three-way ANOVA was used to test the effect of the maternal support environment (MAT), the maternal genotype (family $=$ FAM), and support availability (SUP) on shoot traits of progeny plants. MAT and SUP were fixed factors and FAM was a random factor nested within MAT. Seed size was entered as a covariate. A two-way ANOVA was carried out to evaluate differences in seed size among families (MAT: fixed factor; FAM: random factor nested within MAT) from different maternal environments. The percentage of germination in families of supported and unsupported mother plants was compared with a Mann-Whitney test.

\section{Results}

There was no effect of the maternal environment on seed size at the family level $\left(F_{1,6}=0.059\right.$, $p>0.81$; two-way ANOVA; Means: 11.89 and $12.23 \mathrm{mg}$ for unsupported and supported mothers, respectively). Families within each maternal environment differed in seed size $\left(F_{6,53}=12.26\right.$, $p<0.0001$; two-way ANOVA). Germination percentage was higher in seeds from families of supported mothers (Mean $\pm \mathrm{SE}: 100 \pm 0$ ) than in seeds from families of unsupported mothers (65 \pm 14 ) (adjusted $Z=2.46, p=0.014$; MannWhitney test).

The maternal environment (MAT) did not influence shoot traits but affected phenotypic plasticity in the number of leaves in response to support (SUP) (Table 1). Whereas progeny plants from unsupported mothers (pooling plants from all families) did not show a response to support availability in the number of leaves $\left(F_{1,27}=0.05\right.$, $p>0.82$; one-way ANOVA), progeny from supported mother plants (pooling plants from all families) had a greater number of leaves once support was provided $\left(F_{1,30}=6.74, p=0.014\right.$; one-way ANOVA) (Figure 1). This MAT $\times$ SUP interaction was not explained by seed size because the significance of the effect was very similar with and without seed size as covariate. The maternal genotype (family) within each maternal environment only affected the number of leaves and had no effect on the plasticity of shoot traits (Table 1). Since there was no effect of FAM $\times$ SUP on leaf number (Table 1), the significant MAT $\times$ SUP interaction described above was not consequence of a differential effect on leaf number of the

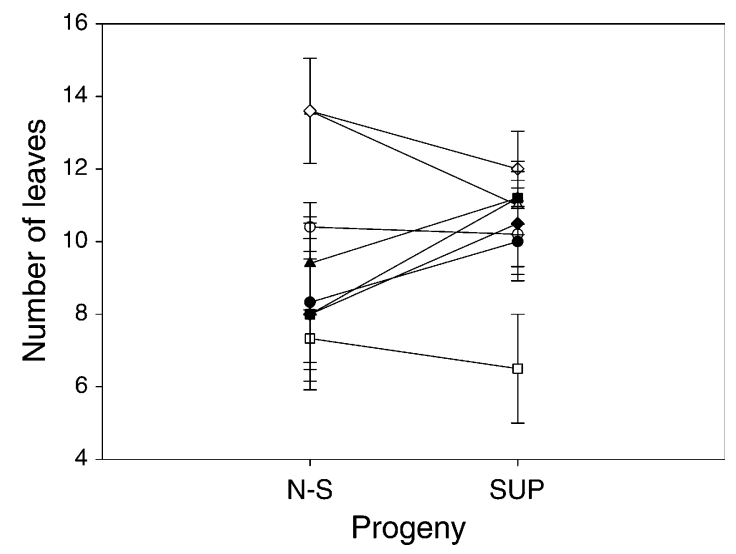

Figure 1. Effect of the maternal environment on the number of leaves (Mean \pm SE) of progeny plants with (SUP) and without (N-S) physical support. Maternal families are identified by different symbols. Filled symbols $=$ families from supported mother plants; Empty symbols $=$ families from unsupported mother plants.

Table 1. Analysis of variance of the effect of maternal support environment (MAT), maternal family (FAM) and support availability (SUP) on shoot traits of I. purpurea.

\begin{tabular}{|c|c|c|c|c|c|}
\hline & $\begin{array}{l}\text { MAT } \\
1,44\end{array}$ & $\begin{array}{l}\text { FAM } \\
6,44\end{array}$ & $\begin{array}{l}\text { SUP } \\
1,44\end{array}$ & $\begin{array}{l}\text { MAT } \times \text { SUP } \\
1,44\end{array}$ & $\begin{array}{l}\text { FAM } \times \text { SUP } \\
6,44\end{array}$ \\
\hline Stem diameter & $0.806(0.712)$ & $0.232(0.201)$ & $0.075(0.061)$ & $0.693(0.930)$ & $0.112(0.167)$ \\
\hline Stem length & $0.908(0.938)$ & $0.609(0.531)$ & $0.668(0.690)$ & $0.188(0.211)$ & $0.476(0.380)$ \\
\hline Internode length & $0.995(0.957)$ & $0.162(0.135)$ & $0.081(0.095)$ & $0.163(0.225)$ & $0.628(0.564)$ \\
\hline Number of branches & $0.636(0.688)$ & $0.441(0.395)$ & $0.139(0.133)$ & $0.718(0.801)$ & $0.120(0.123)$ \\
\hline Number of leaves & $0.418(0.512)$ & $0.017(0.023)$ & $0.089(0.095)$ & $0.008(0.005)$ & $0.940(0.931)$ \\
\hline Shoot biomass & $0.624(0.564)$ & $0.951(0.950)$ & $0.690(0.704)$ & $0.127(0.101)$ & $0.846(0.789)$ \\
\hline Number of flowers & $0.601(0.587)$ & $0.149(0.107)$ & $0.533(0.531)$ & $0.855(0.971)$ & $0.515(0.525)$ \\
\hline
\end{tabular}

MAT and SUP were fixed factors and FAM was a random factor nested within MAT. Seed size was entered as a covariate. $p$-values are shown. Between brackets: $p$-values without considering seed size as a covariate. Significant and marginally not significant $p$-values are shown in bold. Degrees of freedom for each factor (considering the covariate) appear below them. 
particular maternal families included in each of the two maternal environments. The availability of support affected three phenotypic traits of progeny plants, but the effect was marginally non-significant $(0.05<p<0.09)$ (Table 1$)$.

\section{Discussion}

The relative importance of maternal environmental effects vs. maternal genotype on plant phenotype varies with the species and the ecological scenario. For instance, whereas Weiner et al. (1997) found in Centaurea maculosa that the maternal environment (different combinations of herbivory, nutrient shortage and competition treatments) had a small effect on the performance of plants as compared to the maternal genotype, Sultan (1996) reported the opposite for Polygonum persicaria, where offspring traits were greatly affected by the maternal environment (contrasting levels of light, moisture and nutrient availability). In the present study, the maternal genotype (family) only affected seed size and the number of leaves. The effect on leaf number did not vanish once the influence of seed size was 'removed' in the analysis, hence indicating that such an effect was not mediated by seed mass. Furthermore, the absence of a significant Family $\times$ Support interaction on leaf number indicates that the significant statistical interaction found between the maternal and the progeny support environment (see below) was not due to a differential effect on leaf number of the particular maternal families included in each of the two maternal environments.

The maternal environment did not influence seed size but did affect the germination of seeds of Ipomoea purpurea. This suggests that the maternal environment modified the quality of seeds without affecting seed size. Earlier studies have shown maternal effects on seed germination due to several environmental factors (Gutterman 2000), but to our knowledge this is the first report of the effect of support availability in mother plants on seed germination of vine species. This effect might be mediated by mechanisms similar to those underlying the described effects of light quality or fruit position in the mother plant on seed germination (Gutterman 2000). If the lower germination of the progeny of unsupported plants is confirmed to be associated with a higher dormancy (viability of non-germinated seeds was not evaluated, but they seemed identical to germinated ones), then it might be interpreted as a plant strategy enabling seeds to germinate under appropriate environmental conditions, i.e., when physical support is available (Donohue and Schmitt 1998).

The maternal environment had no significant effect on shoot traits of I. purpurea. However, the maternal environment (support) significantly affected the phenotypic plasticity of progeny plants to support availability in terms of leaf number: only progeny plants from supported mothers responded to support availability increasing the production of leaves. This pattern was not mediated by seed size. Provided that such increase in leaf number in supported plants translates into a greater plant performance (e.g. Putz 1984), it might be interpreted as an adaptive maternal environmental effect (Donohue and Schmitt 1998; Agrawal 2001). In a scenario of competition for light with neighbouring plants, an enhanced production of leaves once physical support is located would grant an advantage to vine individuals whose mother plants grew supported in comparison with the progeny of unsupported plants.

Results of the present study are somewhat different to those of preceding work in the same subject on I. purpurea. Thus, the highly significant effects of support availability on shoot traits described earlier (Gianoli 2003) turned to be marginally significant, and the reported effects of the maternal support environment on stem diameter (Gianoli 2002) were not detected. Past and current experiments differed, however, in the phenology of plants and the prevailing environmental conditions (they were conducted in different localities). Although a comparison with previous work was not a goal of the current report, these findings suggest that, as has been shown before (Schmid and Dolt 1994; Wulff et al. 1994), the influence or even the occurrence of maternal environmental effects may vary depending on the environment experienced by progeny plants.

The availability of support is a key ecological factor for vines (Putz and Mooney 1991). The present work, together with earlier studies (Gianoli 2002, 2003), has experimentally assessed some sources of phenotypic variation in vines once a physical support is provided. Future research including field experiments (e.g. Galloway 2001) should help to elucidate the ecological significance of the patterns found. 


\section{Acknowledgements}

We thank Lorena Suárez and Constanza Quiroz for their assistance and Luis J. Corcuera for sharing lab facilities. Comments by Wilfredo L. Gonzáles improved the manuscript. E. Gianoli was supported by Mecesup (UCO-9906) during part of this work.

\section{References}

Agrawal A.A. 2001. Transgenerational consequences of plant responses to herbivory: an adaptive maternal effect? Am. Nat. 157: 555-569.

Austin D.F. and Huamán Z. 1996. A synopsis of Ipomoea (Convolvulaceae) in the Americas. Taxon 45: 3-38.

Donohue K. and Schmitt J. 1998. Maternal environmental effects in plants. In: Mousseau T.A. and Fox C.W. (eds), Maternal Effects as Adaptations. Oxford, Oxford University Press, pp. 137-158.

Galloway L.F. 1995. Response to natural environmental heterogeneity: maternal effects and selection on life-history characters and plasticities in Mimulus guttatus. Evolution 49: 1095-1107.

Galloway L.F. 2001. Parental environmental effects on life history in the herbaceous plant Campanula americana. Ecology 82: 2781-2789.

Gianoli E. 2002. Maternal environmental effects on the phenotypic responses of the twining vine Ipomoea purpurea to support availability. Oikos 99: 324-330.

Gianoli E. 2003. Phenotypic responses of the twining vine Ipomoea purpurea (Convolvulaceae) to physical support availability in sun and shade. Plant Ecol. 165: 21-26.

Gutterman Y. 2000. Maternal effects on seeds during development. In: Fenner M. (ed.), Seeds .The Ecology of Regeneration in Plant Communities. CABI Publishing, New York, pp. 59-84.
Matthei O. 1995. Manual de las malezas que crecen en Chile. Alfabeta, Santiago.

Miao S.L., Bazzaz F.A. and Primack R.B. 1991. Persistence of maternal nutrient effects in Plantago major: the third generation. Ecology 72: 1634-1642.

Platenkamp G.A.J. and Shaw R.G. 1993. Environmental and genetic maternal effects on seed characters in Nemophila menziesii. Evolution 47: 540-555.

Putz F.E. 1984. The natural history of lianas on Barro Colorado Island, Panama. Ecology 65: 1713-1724.

Putz F.E. and Mooney H.A. 1991. The Biology of Vines. Cambridge University Press, Cambridge.

Roach D.A. and Wulff R.D. 1987. Maternal effects in plants. Annu. Rev. Ecol. Syst. 18: 209-235.

Rossiter M. 1996. Incidence and consequences of inherited environmental effects. Annu. Rev. Ecol. Syst. 27: 451-476.

Schlichting C.D. and Pigliucci M. 1998. Phenotypic Evolution: A Reaction Norm Perspective. Sinauer, Sunderland.

Schmid B. and Dolt C. 1994. Effects of maternal and paternal environment and genotype on offspring phenotype in Solidago altissima L. Evolution 48: 1525-1549.

Schmitt J., Niles J. and Wulff R.D. 1992. Norms of reaction of seed traits to maternal environments in Plantago lanceolata. Am. Nat. 139: 451-466.

Sultan S.E. 1996. Phenotypic plasticity for offspring traits in Polygonum persicaria. Ecology 77: 1791-1807.

Weiner J., Martínez S., Müller-Schärer H., Stoll P. and Schmid B. 1997. How important are environmental maternal effects in plants? A study with Centaurea maculosa. J. Ecol. 85: 133 142.

Wulff R.D. and Bazzaz F.A. 1992. Effect of the parental nutrient regime on the growth of the progeny in Abutilon theophrasti (Malvaceae). Am. J. Bot. 79: 1102-1107.

Wulff R.D., Cáceres A. and Schmitt J. 1994. Seed and seedling responses to maternal and offspring environments in Plantago lanceolata. Funct. Ecol. 8: 763-769. 